\title{
Total Hip Arthroplasty the best Intervention for Femur-neck
}

\section{fractures}

Received: 06 May, 2021

Accepted: 15 May, 2021

Published: 17 May, 2021

*Corresponding author: Dr. Suresh Kishanrao, MD DIH, FIAP, FIPHA, FISCD, Visiting Professor, MPH, KSRDPRU, Gadag, Karnataka, India, Tel: 919810631222 ; E-mail:ksuresh.20@gmail.com

https://www.peertechzpublications.com

\section{Check for updates}

\author{
Priya Pralhad Desai ${ }^{1}$ and Suresh Kishanrao ${ }^{2 *}$ \\ 1B/Pharma, MPH, KSRDPRU, Gadag, Karnataka, India \\ ${ }^{2} \mathrm{MD}$, DIH, FIAP, FIPHA, FISCD, Visiting Professor, MPH, KSRDPRU, Gadag, Karnataka, India
}

\begin{abstract}
Fracture neck of femur is a common event in elderly people in India. Total Hip Arthroplasty (THA) has established as the better choice of surgical intervention. There are two major surgical approaches for performing a total hip replacement 1) the posterior approach 2) the anterior approach. The posterior approach to total hip replacement is the most used method and allows the surgeon excellent visibility of the joint, more precise placement of implants and is minimally invasive. In India, cemented modular hemiarthroplasty is being promoted using a cost-effective Indian implant that has confirmed distinct advantage. While the common cause of Femur neck fractures are falls in bathrooms or slipper floors. We are reporting a case of Femur neck fracture, after alighting from a bus. Due to the inaccessibility of THA in rural India, patient had to be shifted to the state Hqs. The course of surgery, hospital stay and outcome of Left side Total Hip Replacement (THR) therapy in an elderly male with known comorbidities is being narrated. The patient had the shortest hospital stay of 5 days, was stable throughout the surgery, postoperative period, despite being diabetic and hypertensive and was back doing his normal activities within 6 months.
\end{abstract}

\section{Background}

The neck of the Femur bone is an anatomical structure linking the shaft with the head and is the weakest link that receives high mechanical pressure whenever the leg lands with force. Femoral neck fractures contribute to nearl

y $50 \%$ of the total hip fractures in India. In elderly individual's trivial traumas like a trip or a fall in the bathroom are responsible for femoral neck fracture mainly due to decreased bone density. Increasing lifespan around the world and consequent osteoporosis, is responsible for higher incidence of hip fractures with each decade of extended life.

Many community-based studies have shown an increase of $76.9 \%$ in the hospitalization register and an average incidence rate of about 2 fractures for every 10,000 older adults. In hospitalized Femur fractures cases, around $70 \%$ of were female, probably due to high prevalence of Osteoporosis after menopause. By 2050 it is estimated that about 6 million people annually will experience a hip fracture.

Globally the management of Femoral Neck Fracture is done either by 1) Non-surgical procedures or 2) surgical procedures.
Non-surgical procedures are opted only in case of any medical contraindication for surgeries or refusal of surgical treatment. They have basic disadvantage of a high bony non-union or mal union, bed sores, pneumonia and deep vein thrombosis and medical complications due to long hospital stay leading to high mortality. 2. Surgical Treatment: Surgical management is the procedure of choice as it facilitates quick recovery. Femur fractures are treated based upon fracture pattern. Femoral neck fractures are typically treated with percutaneous pinning, a sliding hip screw or arthroplasty in elderly patients. Peritrochanteric fractures are typically treated with a sliding hip screw or a cephalomedullary nail [1]. We report one such case of total replacement of Femoral Neck Fracture in an elderly patient, prognosis, and the complete recovery in 6 months.

\section{Case presentation}

Patient: XXX (Male/60 year)

Chief compliant: sever pain in the Left hip region on movement of the left leg (25/12/2018)

History of present illness: An elderly male known case of untreated diabetes mellitus and hypertension but had got pain 
in the left hip region, that began soon after falling from a bus while getting down on 25/12/2018 at around 10pm.The patient was taken to sub-district hospitals and the X-ray of the pelvic confirmed the fracture of the neck of the left femur. Analgesics and traction therapy were applied on that night to relieve the pain. Next day $(26 / 12 / 2018)$ he was shifted to one of the reputed private hospitals in Bengaluru about $300 \mathrm{kms}$ away for further investigation and management Figure 1.

On 27/12/2018 morning the Orthopaedic surgeon examined and advised a Total Hip Arthroplasty (THA) surgery.
Pre-operative diagnosis: fracture neck of left femur.

\section{Investigtions done}

- On 27/12/2018 the followed investigations were doneSerum Creatinine $-1.0 \mathrm{mg} / \mathrm{dL}$

- Electrolytes, Sodium (Na)-141 mM/L, K- $3.9 \mathrm{mM} / \mathrm{L}$ Chloride - $108 \mathrm{mM} / \mathrm{L}$

- Blood urea nitrogen (BUN) - 11mg/dL

- Random blood sugar 124mg/dL
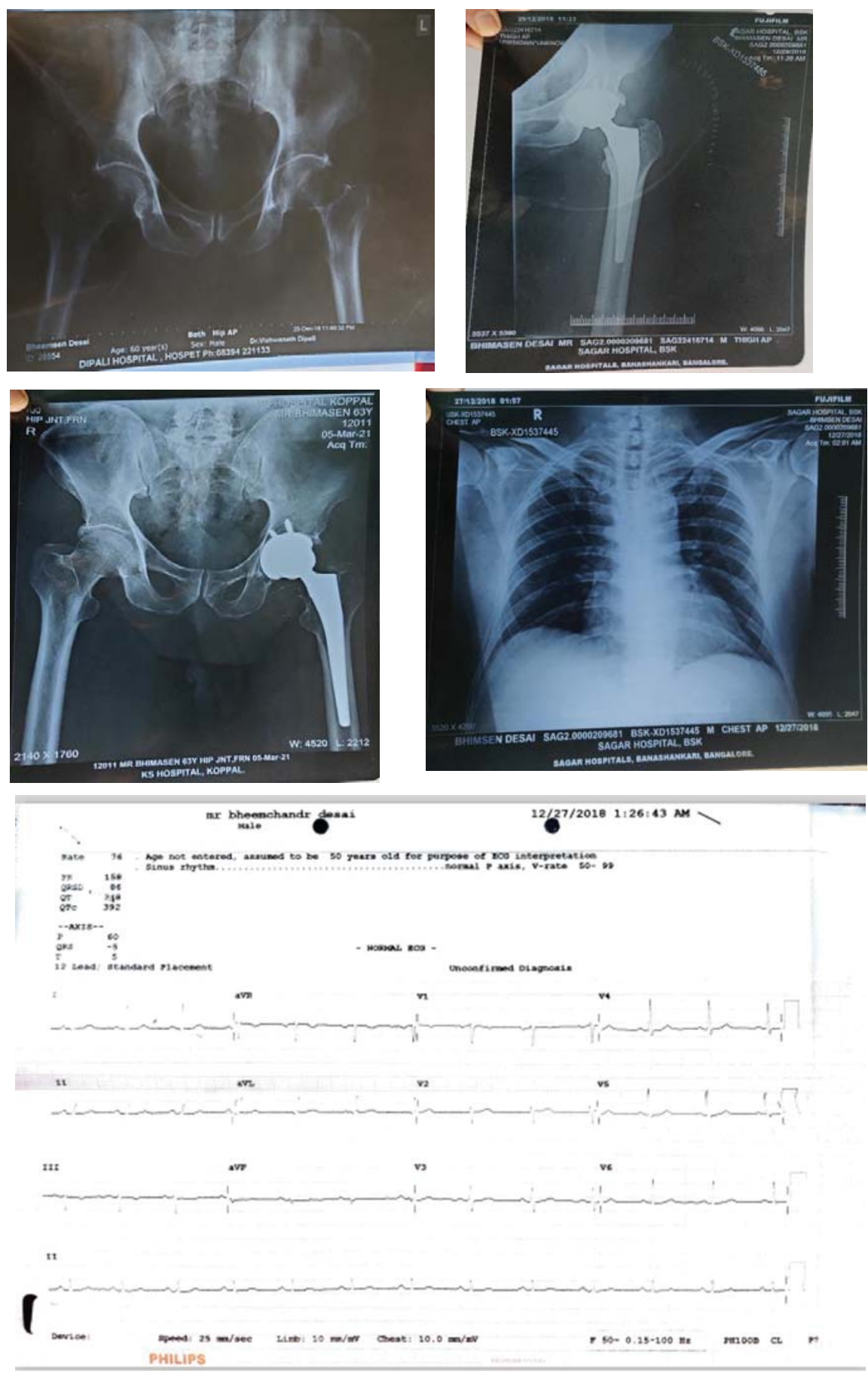

Figure 1: $X^{\prime}$ Rays showing fracture femur and Chest radiography and ECG 
- ECG

- Complete blood count- Hb-13.4 gm/dL(low), haematocrit $\quad-40.9 \%$ (low) $\mathrm{MCH}-\quad 26.5 \mathrm{pg} / \mathrm{mL}$ (low) Eosinophil- $6.2 \%$ (high) remaining tests are within normal rang

- Prothrombin time 18.5 Sec.

- Activated partial thromboplastin time 25.2 Sec

- Blood grouping and Rh typing $\mathrm{O} \mathrm{Rh}+$

- HIV rapid, HCV-Rapid and HBsAg Rapid - all are negative

- VDRL (Rapid syphilis antibody test) - non-reactive

- X-RAY chest AP view.

On $29 / 12 / 2018$

- Urea - $29.96 \mathrm{mg} / \mathrm{dL}$

- Blood urea nitrogen (BUN) - 14mg/dL

- Creatinine $1.1 \mathrm{mg} / \mathrm{dL}$

- Serum Electrolytes, Na - $135 \mathrm{mM} / \mathrm{L}, \mathrm{K}-4.2 \mathrm{mM} / \mathrm{L}$, chloride $-99 \mathrm{mM} / \mathrm{L}$

- Packed cell volume (HCT) - 33.1\%(low)

- Haemoglobin - 11.4 gm/dL(low)

- $\mathrm{X}$-RAY femur AP view.

Surgical Procedure performed: left total hip replacement

Anaesthesia: Under Epidural Spinal Anaesthesia.

\section{Surgery details}

Considering the age and comorbidities of the patient a cemented femoral stem option was decided. This THA prosthesis includes a press-fit acetabular component, neutral polyethylene liner, and CoP head/liner construct [2]. Learning from Indian experience the surgeon opted for Reduction and fixation in lateral position with fluoroscopy in just anteroposterior view. Moore's posterior approach was taken [3]. Under Epidural Spinal Anaesthesia and aseptic precautions, patient was put on right lateral position. Incision was taken from tip of greater trochanter (GT) to backwards. After an incision is made, one finger is placed in sciatic notch \& one finger on anterior superior spine; a line is drawn on drapes between these 2 points with Methylene blue. Another line was drawn between sciatic notch \& anterior spine on the drapes and a 2nd orthogonal line was drawn and flexed an additional 10 degrees [4]. Subcutaneous Bursa was incised, External rotators were tied and cut. Capsule was cut in inverted T shape and head of femur extracted. Acetabulum reaming was done from 38 to 52 size. 52 panache cups with liver (DEPUY) put with 2 screws $(6.5 \mathrm{~mm} \times 25 \mathrm{~mm})$ fixed with good stability Femur side canal entry made [5]. Femur stem trails from 8 to 12 size done. Femur
Coralie stem size 12 (DEPUY) put with metal head $36 \mathrm{~mm}$ fixed, checked stability. The resulting leg length discrepancy was hardly $0.3 \mathrm{~mm}$. A thorough wash given. Homeostasis achieved; closure done in layers. Aseptic dressing done. Patient withstood the procedure well.

\section{Post-operative care}

Postoperatively patient was stable. Patient was treated with Inj.Clexane, Inj.Paracip, Inj.Pantaprazole, Tab.Ecosprin, Tab.Ceftum and other supportive measures. Patient was haemodynamically stable and hence he was discharged on the 2/1/2019 with continued medication and follow-up after 1 week.

\section{Outcome and follow-up}

On $10^{\text {th }}$ January 2019 visited hospital for follow-up. The patient was advised Ambulation with walker and Quadriceps strengthening exercises and medications. The medications include Tab.Ceftum 500mg (1-0-1x7 days, after food), Tab. Pantocid 40mg (1-0-0x10 days, before food), Tab.Ultracet (10-1X10 days after food), Tab.Ecosprin 150mg (0-1-0×30 days, after food), Tab.Narvijen NP (0-0-1x10 days, after food), Tab. Glycomet GP1 (1-0-1x to continue), Tab. Amlong 2.5 mg (1-0ox to continue).

On 15/1/2019 visited hospital for stich removal. The wound was completely healed. Continuation of Physiotherapy was advised for another 4 weeks.

The restriction of bending of hips, knee more than 90 degree, crossing the legs, lifting the leg to put on socks and sitting on the floor with leg crossed was continued. After 6 months he is walking without any aids and was able to do what he did before the event. Most importantly quality of the life was good.

On 3/3/2021 (after one year eight months) the patient started complaining of pain in the left hip joint which gradually increased on the next day and he could not move and lift the leg. (probably due to excessive travelling and over physical strain) Therefore, he went to the hospital on 5/3/2021 at Koppal. The $\mathrm{x}$-ray did not show any abnormality in the operated left hip joint, analgesics and anti-ulcer drugs were given through IV for three days. Pain disappeared completely and he could move his leg and walk, therefore discharged on 7/3/2021 with the following advice.

1. Rest for 15 days

2. Diet and physical exercise

3. Tab Ultracet $1-0-1 \times$ five days

4. Tab PAN $40 \mathrm{mg}$ 1-0-0 $\times$ five days, before food.

\section{Discussion}

Human beings standing and walking depends upon the long bones of legs. The weakest link of the femur is the neck that connects head to the shaft. Proximal femur fracture is one of the more serious health problems that affect patients of 
advanced age. Trauma due to fall or a simple trip is the most common cause of femoral neck fractures [6]. In hospitalized Femur fractures cases, around $70 \%$ of were female, probably due to high prevalence of Osteoporosis after menopause. A study in Delhi estimated the prevalence of osteoporosis as $24.6 \%$ in men and $42.5 \%$ in women above 40 years of age [7]. Neeraj Kumar Agrawal et al reported based on density of femur neck that density decreased with age; there was osteoporosis in $8.5 \%$, osteopenia in $42 \%$. Vitamin D deficiency is attributed to be the cause of osteoporosis [8]. Another study by Sharma et al. has reported a prevalence of $8.5 \%$ in the femoral neck region in men, In India common cause is a fall in the bathroom or getting down from a staircase. In the case we are reporting an impact while getting down from a Bus on an uneven surface of the bus stand was the cause of the fracture.

A prospective analysis of 54 cases of femoral neck fractures treated between December 2015 and November 2017, the aetiology was a fall. Dynamic Compression Locking System (DCLS) and Multiple Cannulated Compression Screw (MCCS) methods of the treatment of femoral neck fractures were compared, that showed no significant difference in followup time, operation time, incision length, surgical blood loss, the incidence of perioperative and postoperative healing complications, and mobility in the two groups. But the fracture healing rate in the DCLS group was higher than that in the MCCS group [9]. In our case the prostheses for a Total Hip Arthroplasty (THA) were inserted into the pelvis and femur with cement. Physiotherapy is an essential part of rehabilitation after a total hip replacement.

In a retrospective study, comparing THA and hemiarthroplasty done between 2010-2015 in an institution the average survival time was 33.9 months and 19.07 months, respectively. At the final follow up 19\% patient were deceased with no gender disparity. Risk of mortality increased with increasing age. The risk of mortality was 7 times greater hemiarthroplasty group. The mean survival of patients was less than 3 years, and it was influenced by the presence of comorbidities. The risk was significantly greater after hemiarthroplasty, even after adjusting for age of the patient. There was no association between prosthesis and functional characteristics and quality of life post-operatively [10].

A similar study in an Indian Hospital over a period of 2 years from January 2010 till December 2011, of 119 patients treated with cemented modular hemiarthroplasty using a costeffective Indian implant. Of the 63 males and 56 females with a mean age of 70.7 years (range 55-98 years), and 42 of them having hypertension and 29 having diabetes were followed for a period of 12 to 37 months with an average of 24 months. Most of the surgeries (60\%) were performed within 24 hours of admission. The mean length of hospital stay was 10.4 days (range 3-24 days) with $77 \%(n=92)$ of patients were discharged within 1 week of admission. Our case experience is comparable with this study. On follow-up, $76 \%$ of patients had returned to the preinjury ambulatory status, so was our case [11].

A study that assessed the Quality-of-Life (QOL) of elderly ( $>60$ years) in 21 untreated hip fractures in a rural developmental block in Southern India compared with a control group, matched for age and sex among neighbourhood people. It inferred that the QOL scores was poor among people with untreated fracture neck of the femur as compared with the comparison group and as compared to their own status before the occurrence of the event. Many participants reported severe problems with mobility, pain, usual activity and self-care and anxiety domains of EQ-5D questionnaire [12].

Two thirds of THAs are performed in patients over 65 years of age. $90 \%-95 \%$ of patients can expect to have their total hip replacement functioning at 10 years, and in $85 \%$ they will still be functioning at 20 years.

There are some apprehensions expressed over Total Hip Arthroplasty (THA) surgeries of patients in their mid-twenties might lead to many revisions in their later life and eventually to unmanageable anatomic situations, but this fear appears to be unfounded. Though THA was initially designed to be performed in elderly low-demanding patients, the benefit of the procedure in younger populations has also been well documented.

Hip replacement is occasionally performed in patients in their teens and early twenties. In this age group its most successful indication has been in relieving pain and improving function in patients with debilitating childhood inflammatory arthritis. In a retrospective review of Thirty patients (45 hips) with various indications for THA based on radiological and clinical and analysing survival, reasons of failure, factors associated with outcomes and postoperative complications showed excellent long term outcomes of THA in patients younger than 30 years of age, comparable with those in older patients [13].

\section{Conclusion}

Fracture of the neck of the femur is the commonest Hip fractures in India

Femoral neck fractures are typically treated with either THA or hemiarthroplasty

The THA therapy has the merits of High success rate Immediate relief of the pain, and Improved mobility and hip function.

After the operation pain gets relieved immediately and patient will be mobile immediately with aids and after 2-6 months he could move without any aids.

This concept of measuring quality of life is especially important in hip fracture, it influences the person's way of living, goals, expectations, standards, and concerns, all of which meriting timely replacement of hip.

\section{Take home messages}

Total Hip Arthroplasty (THA) is the best surgery for Neck fractures of the Femur irrespective of the age of the cause of the fracture.

\section{Indian THA implants are cost effective}

Apart from immediate pain relief, minimal post-operative 
complications, long term outcomes among all age groups are excellent.

\section{References}

1. Shu DP, Xiao YP, Bei MJ, Ji T, Peng YJ, et al. (2020) Dynamic compression locking system versus multiple cannulated compression screw for the treatment of femoral neck fractures: a comparative study. BMC Musculoskeletal Disord 21:1-9. Link: https://bit.ly/3bN81UX

2. Hamid $P$, Valizadeh $S$, Saeed Banadaky $\mathrm{SH}$, Akhavan Karbasi MH, Abrisham SMJ, et al. (2014) Management of Hip Fractures in Lateral Position without a Fracture Table. Arch Bone Jt Surg 2: 168-173. Link: https://bit.ly/3eNP4TR

3. Kofoed H, Kofod J (1983) Moore prosthesis in the treatment of fresh femoral neck fractures: A critical review with special attention to secondary acetabular degeneration. Injury 14: 531-540. Link: https://bit.ly/3uROOc2

4. Varacallo M, Luo TD, Johanson NA (2021) Total Hip Arthroplasty Techniques. Link: https://bit.ly/3eNvreu

5. THR: Acetabular Reaming. Link: https://bit.ly/2SL8TT4

6. Iglesias SL, Gentile L, Vanoli F, Mangupli MM, Pioli I, et al. (2017) Femoral neck fractures in the elderly: from risk factors to prognostic features for survival. Journal of Trauma and Critical Care 1: 1-6. Link: https://bit.ly/3bxx26m
7. Kadam NS, Chiplonkar SA, Khadilkar AV, Khadilkar VV (2018) Prevalence of osteoporosis in apparently healthy adults above 40 years, in Pune City, India. Indian J Endocrinol Metab 22: 67-73. Link: https://bit.ly/33MzOQL

8. Agrawal NK, Sharma B (2013) Prevalence of osteoporosis in otherwise healthy Indian males aged 50 years and above. Arch Osteoporos 8: 116. Link: https://bit.ly/2SJm8nh

9. Shu DP, Xiao YP, Bei MJ, Ji T, Peng YJ, et al. (2020) Dynamic compression locking system versus multiple cannulated compression screw for the treatment of femoral neck fractures: a comparative study. BMC Musculoskeletal Disorders 21: 230. Link: https://bit.ly/3okHK5e

10. Gebhard JS, Amstutz HC, Zinar DM, Dorey FJ (1992) A comparison of total hip arthroplasty and hemiarthroplasty for treatment of acute fracture of the femoral neck. Clin Orthop Relat Res 123-131. Link: https://bit.ly/3tXp7FS

11. Jain D, Sidhu GS, Selhi HS, Mears SC, Yamin M, et al. (2015) Early Results of a Geriatric Hip Fracture Program in India for Femoral Neck Fracture. Geriatr Orthop Surg Rehabil 6: 42-46. Link: https://bit.ly/3eOXKsV

12. Prasad JD, Varghese AK, Jamkhandi D, Chakraborty A, Rakesh PS, et al. (2013) Quality-of-life among elderly with untreated fracture of neck of femur: A community- based study from southern India. J Family Med Prim Care 2: 270-273. Link: https://bit.ly/3fmwxNp

13. Pakos EE, Paschos NK, Xenakis TA (2014) Long Term Outcomes of Total Hip Arthroplasty in Young Patients under 30. Arch Bone Jt Surg 2: 157-162. Link:

\section{Discover a bigger Impact and Visibility of your article publication with}

\section{Peertechz Publications}

\section{Highlights}

* Signatory publisher of ORCID

* Signatory Publisher of DORA (San Francisco Declaration on Research Assessment)

- Articles archived in worlds' renowned service providers such as Portico, CNKI, AGRIS, TDNet, Base (Bielefeld University Library), CrossRef, Scilit, J-Gate etc.

* Journals indexed in ICMJE, SHERPA/ROMEO, Google Scholar etc.

* OAI-PMH (Open Archives Initiative Protocol for Metadata Harvesting)

* Dedicated Editorial Board for every journal

* Accurate and rapid peer-review process

* Increased citations of published articles through promotions

* Reduced timeline for article publication

Submit your articles and experience a new surge in publication services (https://www.peertechz.com/submission).

Peertechz journals wishes everlasting success in your every endeavours.

Copyright: @ 2021 Priya PD, et al. This is an open-access article distributed under the terms of the Creative Commons Attribution License, which permits unrestricted use distribution, and reproduction in any medium, provided the original author and source are credited. 